\title{
The Effects of Dexmedetomidine Added to Spinal bupivacaine for lower limb surgery
}

\author{
Feroz Ahmad Dar ${ }^{1}$, Hilal Ahmad Bhat ${ }^{2}$, Tasaduq Javeed ${ }^{3}$, Mohd Rafiq Najar ${ }^{4}$ \\ ${ }^{I}$ Feroz Ahmad Dar (M.D), SKIMS Medical College and Hospital \\ ${ }^{2}$ Hilal Ahmad Bhat (D.A), SKIMS Medical College and Hospital \\ ${ }^{3}$ Tasaduq Javeed (D.A), SKIMS Medical College and Hospital \\ ${ }^{4}$ Mohd Rafiq Najar (D.A), SKIMS Medical College and Hospital
}

\begin{abstract}
:
Background: Intrathecal $\alpha 2$ agonists prolong the duration of action of local anesthetics and reduce the required dose. Dexmedetomidine is a $\alpha 2$ receptor agonist and its $\alpha 2 / \alpha 1$ selectivity is 8 times higher than that of clonidine.

Aims: In this study, we aimed to investigate the effect of adding dexmedetomidine to intrathecal bupivacaine on the onset time and duration of motor and sensory blocks.

Methods: Patients were randomly assigned into two groups. Group B $(n=30)$ patients received $3 \mathrm{ml}(15 \mathrm{mg})$ of $0.5 \%$ bupivacaine $+0.5 \mathrm{ml}$ normal saline and Group BD $(n=30)$ patients received $3 \mathrm{ml}(15 \mathrm{mg})$ of $0.5 \%$ bupivacaine $+0.5 \mathrm{ml}(5 \mu \mathrm{g})$ dexmedetomidine. The parameters studied were - onset and total duration of sensory block, onset and total duration of motor block, the most elevated dermatome level, hemodynamic alterations, and any intraoperative and postoperative complications.

Results: The two groups were matched for demographic data. Sensory and motor block onset times were similar in both groups. The regression of the sensory block to S1 dermatome and regression of complete motor block were longer in Group BD than Group B $(p<0.001)$. No significant difference were seen between the groups relative to the maximum level of sensory block $(p=0.340)$. Statistically there were no significant differences in hemodynamic alterations and other adverse effects between the groups.

Conclusion: We conclude that intrathecal dexmedetomidine addition to bupivacaine for spinal anaesthesia prolongs sensory and motor block durations without any significant adverse effects.
\end{abstract}

Key Words: Dexmedetomidine, bupivacaine, spinal block

\section{Introduction}

While spinal anaesthesia has many advantages, the limited duration of action appears to be one of its downsides. Intrathecal $\alpha 2$ agonists prolong the duration of action of local anaesthetics and reduce the required dose. The intrathecal use of clonidine, a partial $\alpha 2$ adrenoceptor agonist, has been shown as an effective and safe procedure $(1,2)$. Dexmedetomidine is a $\alpha 2$ receptor agonist and its $\alpha 2 / \alpha 1$ selectivity is eight times higher than that of clonidine. In animal models, intrathecal dexmedetomidine has been demonstrated to have an analgesic effect $(3,4)$. In this study, we aimed to investigate the influences of dexmedetomidine added to bupivacaine on the time of onset of spinal block and durations of sensory and motor blocks in patients undergoing lower limb surgery under spinal anaesthesia.

\section{Materials and Methods}

With the approval of ethics committee of the institution, 60 patients of ASA grade I- II of either sex in the age range of 20 to 50 years, undergoing lower limb surgery (below knee including arthroscopy of knee) under spinal anaesthesia were selected for the study and these were divided into two groups of 30 patients each. Using the sealed envelope method, the patients were randomly allocated into two groups: Group B $(n=30)$ or Group BD $(n=30)$. Patients who were taking $\alpha$-adrenergic agonist or antagonist therapy, as well as patients who had labile hypertension, autoimmune disorders, known allergy to study drugs, heart block or any contraindication to spinal anaesthesia were excluded from the study. After arrival at the operating theatre, baseline systolic blood pressure (SBP), diastolic blood pressure (DBP), mean arterial pressure (MAP), heart rate $(\mathrm{HR})$ measurements, peripheral oxygen saturation $(\mathrm{SpO} 2)$ and electrocardiography monitoring were measured by an anaesthesiologist who was blind to group allocation. After prehydration with $10 \mathrm{ml} / \mathrm{kg}$ of normal saline, we performed dural puncture between L3-4 or L4-5 interspace, under sterile conditions and with the patients in the sitting position, through a 25 -gauge Quincke needle. Group B received $3 \mathrm{ml}$ of bupivacaine $0.5 \%$ hyperbaric (Anawin Heavy; Neon Laboratory Ltd. India) with $0.5 \mathrm{ml}$ of normal saline in spinal anaesthesia and group BD received $3 \mathrm{ml}$ of hyperbaric bupivacaine $0.5 \%$ with $0.5 \mathrm{ml}(5 \mu \mathrm{g})$ of dexmedetomidine (Dextomid; Neon Labs, India) in spinal anaesthesia. Standard monitoring was continued throughout the operation. Sensory blockade was 
assessed by using pinprick test on each side of the midclavicular line; motor blockade was assessed based on a modified Bromage scale (5) $(0=$ free movement of legs and feet, $1=$ just able to flex knees with free movement of feet, $2=$ unable to flex knees, but with free movement of feet, $3=$ unable to move legs or feet). The sensory level and Bromage scale were recorded intra-operatively every $2 \mathrm{~min}$ for a period of $20 \mathrm{~min}$, at the end of the surgery and in the Post-Anaesthesia Care Unit (PACU) every 15 min until the patient was discharged from PACU by an anaesthesiologist who was blinded to group allocation. Further testing was recorded at 15 minute intervals until the recovery of S1 dermatome. Sensory block onset time to T10 dermatome, the highest dermatomal level, sensory block complete regression time, motor block onset time, reaching Bromage 3 and regression to Bromage 0 times were recorded. The haemodynamic variables were recorded before spinal anaesthesia and thereafter every $2 \mathrm{~min}$ for $10 \mathrm{~min}$, every $5 \mathrm{~min}$ until the end of the procedure in the operating room and every $15 \mathrm{~min}$ in the PACU until the patient was discharged to the ward. Follow-up was carried out 5 days postoperatively by the blinded anaesthetist who asked about any neurological deficits secondary to spinal anaesthesia. A decrease $>20 \%$ from baseline, or to $<90 \mathrm{mmHg}$ in systolic blood pressure, was defined as hypotension and was treated with incremental doses of $5 \mathrm{mg}$ intravenous ephedrine. Bradycardia was defined as heart rate $<50$ beats/min and was treated with atropine. Intraoperative analgesic requirement, intraoperative and postoperative nausea and vomiting and other side effects were recorded.

Intergroup comparison of demographic data, durations of sensory and motor blocks, mean arterial pressure, and mean heart rate values were carried out by Student's t test, whereas intragroup comparisons were performed with Repeated Measure ANOVA test. Chi-square or Fisher's Exact Test, as appropriate, were applied for intergroup analysis of side effects. Values of $\mathrm{p}<0.05$ were accepted as statistically significant. Determination of patient number was made according to the study of Kanazi et al. (2). A minimum of 13 patients in each group was recruited according to the power analysis ( $\alpha=0.05$ and, $\beta=0.05$, power $95 \%$ ).

\section{Results}

The two groups were matched for demographic data and duration of operation (Table 1).

\begin{tabular}{|l|c|c|c|}
\hline Table 1. Characteristics of patients :- & Group B (n=30) & P value \\
\hline & $30.2 \pm 5.1$ & $29.3 \pm 6.7$ & 0.561 \\
\hline Age (years) & $172 \pm 6.1$ & $169 \pm 6.3$ & 0.099 \\
\hline Height $(\mathrm{cm})$ & $62 \pm 5.1$ & $66 \pm 3.2$ & 0.439 \\
\hline Body weight (kg) & $90.2 \pm 30.2$ & $98 \pm 28.3$ & 0.089 \\
\hline Duration of surgery (min) & $\mathrm{p}$ values calculated using Student's t- test \\
\hline \multicolumn{4}{|l}{} \\
\hline
\end{tabular}

Time for sensory block to reach T10 level was similar in both the groups $(\mathrm{p}=0.296)$. There was no difference between the groups relative to the maximum level of sensory block $(\mathrm{p}=0.340)$. In both groups, all patients demonstrated complete motor block (Bromage 3). Time to reach complete motor block was similar in both of the groups $(\mathrm{p}=0.856)$. Time to regression of the sensory block to $\mathrm{S} 1$ dermatome and time to complete recovery of motor block was more prolonged in Group BL than in Group B and the intergroup difference was statistically significant $(\mathrm{p}<0.001)$ (Table 2).

\begin{tabular}{|c|c|c|c|}
\hline & Group B $(n=30)$ & Group BD (n=30) & $\mathrm{P}$ value \\
\hline Time to sensory block to reach T10 dermatome (min) & $7.5 \pm 2.7$ & $8.3 \pm 3.3$ & 0.296 \\
\hline Highest level of sensory block (T) & $8.6 \pm 1.0$ & $8.2 \pm 2.0$ & 0.340 \\
\hline Time to onset of complete motor block (Bromage $=3)(\mathrm{min})$ & $14.3 \pm 7.1$ & $13.9 \pm 6.9$ & 0.856 \\
\hline Time to sensory regression to S1 segment (min) & $226.6 \pm 26.4$ & $356.3 \pm 35.2$ & $<0.001$ \\
\hline Time to motor block regression to Bromage 0 & $201.0 \pm 26.9$ & $332.0 \pm 36$ & $<0.001$ \\
\hline
\end{tabular}

\begin{tabular}{|l|c|c|c|}
\hline Table 3: Adverse effects:- \\
\hline & Group B (n=30) & Group BD (n=30) & P value \\
\hline Hypotension & 0 & 2 & 0.492 \\
Nausea & 1 & 2 & 1.00 \\
Vomiting & 1 & 1 & 1.00 \\
Bradycardia & 3 & 2 & 1.00 \\
\hline \multicolumn{4}{|c|}{} \\
\hline
\end{tabular}


There was no difference between the groups with regard to mean arterial pressure values at baseline and during all time points ( $p>0.05)$ (figure1). There was no statistically significant difference between the groups relative to baseline HR values ( $p>0.05$ ) (figure 2). The comparison of HR values at baseline and at other time points both in Group B and Group BD did not show any statistically significant difference ( $>0.05)$. Adequate nerve block was established in both groups and none of the patient's required additional analgesia. None of the patients had an observed neurological deficit or any transient neurogical symptoms at the postoperative follow-up. The side effects that were observed in the groups are summarised in Table 3. No statistically significant difference was determined between the groups with regard to the frequency of side effects.
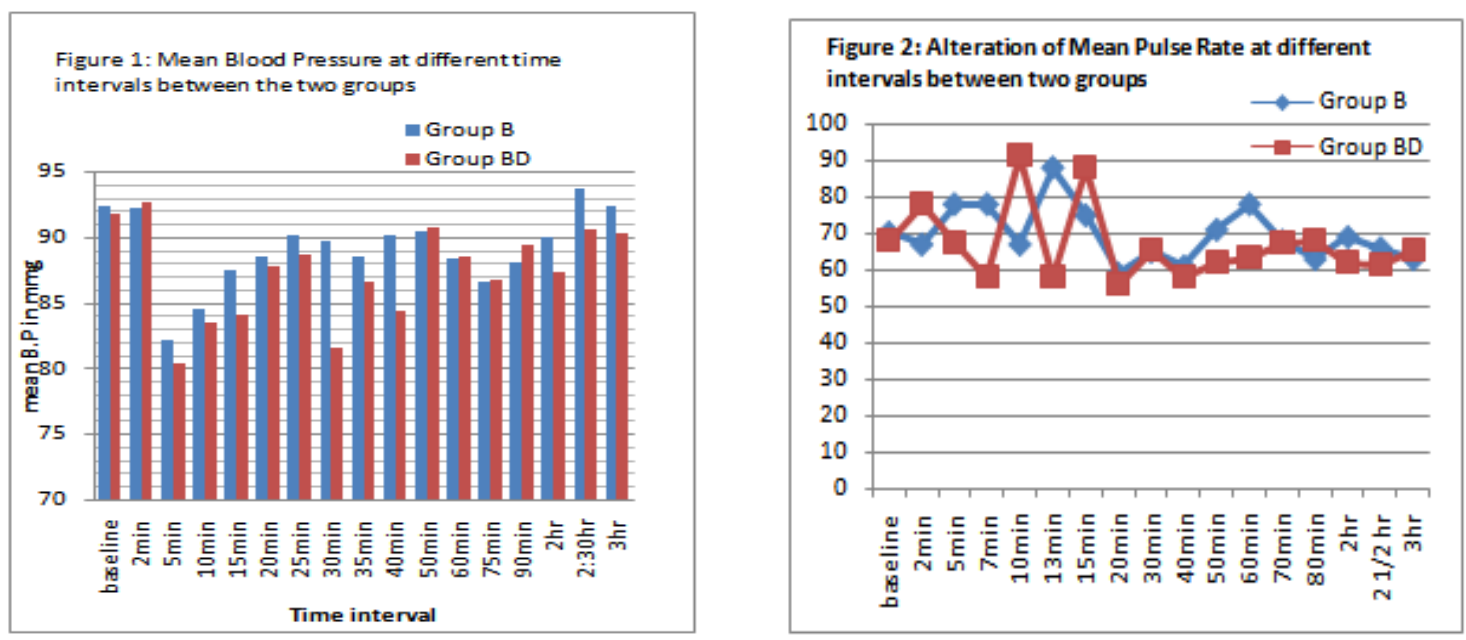

\section{Discussion}

In this study, we observed that adding dexmedetomidine to bupivacaine prolonged the sensory and motor block duration in patients subjected to lower limb surgery under spinal anaesthesia. Although the mechanism is unclear, $\alpha 2$ adrenoceptor agonists have been observed to extend the sensory and motor block durations of local anaesthetics. Ossipov et al. (6) conducted a study where they delivered intrathecal clonidine to rodents and reported that adrenergic receptor agonists induced analgesia by a mechanism other than that of opioids. Clonidine increases acetylcholine concentration in cerebrospinal fluid and activates $\alpha 2$ adrenergic receptors in the dorsal horn of the spinal cord (7). The $\alpha 2$ adrenoceptors are localised over the primary afferent terminals of neurons in the superficial lamina of the spinal cord and in the nuclei of the brainstem associated with pain. This localisation supports that $\alpha 2$ agonists show their analgesic effects through both peripheral and central pathways (8). Clonidine, an intrathecal $\alpha 2$ adrenoceptor agonist, has been used intrathecally in many studies which provided adequate clinical experience about the agent; studies focusing on intrathecal use of dexmedetomidine and its combined use with local anaesthetics are not sufficient $(1,9,10)$. Although dexmedetomidine has been approved by the Food and Drug Administration as a sedative for mechanically-ventilated adult intensive care unit patients, it has not been approved for intrathecal use. However, dexmedetomidine used in neuraxial blocks in experimental and clinical studies without neurological deficits has encouraged the use of dexmedetomidine by the intrathecal route with bupivacaine $(2,11-20)$. The intrathecal application of dexmedetomidine in the 2.5-

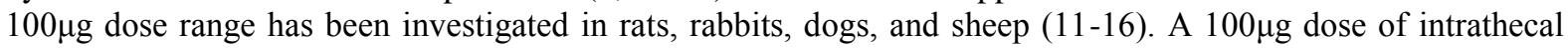
dexmedetomidine was employed in sheep but no neurological deficit was observed during a follow-up period of 7 days (11). In the study of Strebel et al. (1) on orthopaedic cases, using clonidine at a dose below $150 \mu \mathrm{g}$ in combination with isobaric bupivacaine in a dose-dependent fashion was shown to provide significantly prolonged duration of spinal anaesthesia and analgesia without disrupting the haemodynamic stability and inducing sedation. Santiveri et al. (21) used $75 \mu \mathrm{g}$ clonidine to prilocaine in patients undergoing transurethral resection of bladder tumours under spinal anaesthesia and reported prolonged sensory and motor blocks along with reduced postoperative analgesic requirement. De Kock et al. (9) used spinal anaesthesia by adding varying doses of clonidine $(0,15,45 \mathrm{or} 75 \mu \mathrm{g})$ to ropivacaine in arthroscopy patients. The quality of anaesthesia was lower in the ropivacaine-only group, the quality of intraoperative analgesia was elevated while motor and sensory block durations were unchanged in the $15 \mu \mathrm{g}$ clonidine group, and sensory block duration was prolonged in the $75 \mu \mathrm{g}$ clonidine group. Kanazi et al. (2) reported that the addition of dexmedetomidine ( $3 \mu \mathrm{g})$ or clonidine $(30 \mu \mathrm{g})$ to bupivacaine in spinal block shortens the time to onset of motor block and extends the sensory and motor block durations. Al-Mustafa et al. (17) added 5 $\mu \mathrm{g}$ and $10 \mu \mathrm{g}$ dexmedetomidine to spinal bupivacaine and noted shorter times to onset of sensory and motor blocks along with longer block durations. Gupta et al. (20) 
added $5 \mu \mathrm{g}$ dexmedetomidine or $25 \mu \mathrm{g}$ fentanyl to $12.5 \mathrm{mg}$ bupivacaine in spinal blocks and noted a longer duration of both sensory and motor blockade, and good patient satisfaction. Niemi et al. (22) reported that the addition of clonidine to bupivacaine in spinal anaesthesia prolonged block duration, but decreased the mean blood pressure and heart rate significantly compared with the control group. Kanazi et al. (2) noted that dexmedetomidine or clonidine added to intrathecal bupivacaine did not cause a significant reduction in blood pressure. In the study of Gupta et al. (20), hypotension was more severe in the dexmedetomidine group than in the fentanyl group, but no statistically significant difference was determined between the groups. In this study, we observed hypotension and bradycardia in only 2 patients.

In conclusion, the combined use of $5 \mu \mathrm{g}$ dexmedetomidine and bupivacaine in spinal anaesthesia prolongs sensory and motor block durations without causing any significant side effects.

Conflict of Interest: No conflict of interest was declared by the authors.

\section{References}

[1]. Strebel S, Gurzeler JA, Schneider MC, Aeschbach A, Kindler CH. Small-dose intrathecal clonidine and isobaric bupivacaine for orthopedic surgery: a dose-response-study. Anesth Analg 2004;99:1231-38.

[2]. Kanazi GE, Aouad MT, Jabbour-Khoury SI, Al Jazzar MD, Alameddine MM, Al-Yaman R, et al. Effect of low-dose dexmedetomidine or clonidine on the characteristics of bupivacaine spinal block. Acta Anaesth Scand 2006;50:222-7.

[3]. Kalso E, Poyhia R, Rosenberg P. Spinal antinociception by dexmedetomidine, a highly selective alpha 2- adrenergic agonist. Pharmacol Toxicol 1991;68:140-3.

[4]. Foster RH, Markham A. Levobupivacaine: A Review of its pharmacology and use as a local anaesthetic. Drugs 2000;59:531-79.

[5]. Bromage PR. Epidural Anesthesia. Philadelphia, WB Saunders, 1978, 144.

[6]. Ossipov MH, Suarez LJ, Spaulding TC. Antinociceptive interactions between alpha 2 adrenergic and opiate agonists at the spinal level in rodents. Anesth Analg 1989;68:194-200.

[7]. Hood DD, Mallak KA, Eisenach JC, Tong C. Interaction between intrathecal neostigmine and epidural clonidine in human volunteers. Anesthesiology 1996;85:315-25.

[8]. Eisenach JC, De Kock M, Klimscha W. alpha (2)-adrenergic agonists for regional anesthesia. A clinical review of clonidine (19841995). Anesthesiology 1996;85:655-74.

[9]. De Kock M, Gautier P, Fanard L, Hody JL, Lavand'homme P. Intrathecal ropivacaine and clonidine for ambulatory knee arthroscopy: a dose-response study. Anesthesiology 2001;94:574-8.

[10]. Dobrydnjov I, Axelsson K, Samarutel J, Holmstrom B. Postoperative pain relief following intrathecal bupivacaine combined with intrathecal or oral clonidine. Acta Anaesthesiol Scand 2002;46:806-14.

[11]. Eisenach JC, Shafer SL, Bucklin BA, Jackson C, Kallio A. Pharmacokinetics and pharmacodynamics of intraspinal dexmedetomidine in sheep. Anesthesiology 1994;80:1349-59.

[12]. Talke P, Xu M, Paloheimo M, Kalso E. Effects of intrathecally administered dexmedetomidine, MPV-2426 and tizanidine on EMG in rats. Acta Anaesthesiol Scand 2003;47:347-54.

[13]. Xu M, Kontinen VK, Kalso E. Effects of radolmidine, a novel alpha2- adrenergic agonist compared with dexmedetomidine in different pain models in the rat. Anesthesiology 2000;93:473-81.

[14]. Horvath G, Joo G, Dobos I, Klimscha W, Toth G, Benedek G. The synergistic antinociceptive interactions of endomorphin-1 with dexmedetomidine and/or S(+)-ketamine in rats. Anesth Analg 2001;93:1018-24.

[15]. Onttonen T, Pertovaara A. The mechanical antihyperalgesic effect of intrathecally dministered MPV-2426, a novel alpha2adrenoceptor agonist, in a rat model of postoperative pain. Anesthesiology 2000;92:1740-5.

[16]. Takano Y, Yaksh TL. Characterization of the pharmacology of intrathecally administered alpha 2-agonists and antagonists in rats. $\mathrm{J}$ Pharmacol Exp Ther 1992;261:764-72.

[17]. Al-Mustafa MM, Abu-Halaweh SA, Aloweidi AS, Murshidi MM, Ammari BA, Awwad ZM, et al. Effect of dexmedetomidine added to spinal bupivacaine for urological procedures. Saudi Med J 2009;30:365-70.

[18]. Al-Ghanem SM, Massad IM, Al-Mustafa MM, Al-Zaben KR, Qudaisat IY, Qatawneh AM, et al. Effect of Adding Dexmedetomidine versus Fentanyl to Intrathecal Bupivacaine on Spinal Block Characteristics in Gynecological Procedures: A Double Blind Controlled Study. Am J Appl Sci 2009;6:882-7.

[19]. Gupta R, Bogra J, Verma R, Kohli M, Kushwaha JK, Kumar S. Dexmedetomidine as an intrathecal adjuvant for postoperative analgesia. Indian J Anaesth 2011;55:347-51.

[20]. Gupta R, Verma R, Bogra J, Kohli M, Raman R, Kushwaha JK. A Comparative study of intrathecal dexmedetomidine and fentanyl as adjuvants to Bupivacaine. J Anaesthesiol Clin Pharmacol 2011;27:339-43.

[21]. Santiveri X, Arxer A, Plaja I, Metje MT, Martinez B, Villalonga A, et al. Anaesthetic and postoperative analgesic effects of spinal clonidine as an additive to prilocaine in the transurethral resection of urinary bladder tumours. Eur J Anaesth 2002;19:589-93.

[22]. Niemi L. Effects of intrathecal clonidine on duration of bupivacaine spinal anaesthesia, haemodynamics and postoperative analgesia in patients undergoing knee arthroscopy. Acta Anaesthesiol Scand 1994;38:724-8. 